Ethiopian Journal of Environmental Studies \& Management 7 Suppl.: 810 - 820, 2014.

ISSN:1998-0507

doi: http://dx.doi.org/10.4314/ejesm.v7i2.1S

Submitted: March 11, 2014

Accepted: November 15, 2014

\title{
ASSESSING FACTORS AFFECTING ADHERENCE TO SAFETY PRECAUTIONS IN PESTICIDES USE AMONG COCOA FARMERS IN NIGERIA
}

\author{
*OWOMBO, P.T., ${ }^{1}$ IDUMAH, F.0. ${ }^{1}$ AND AFOLAYAN, A. F. ${ }^{2}$ \\ ${ }^{1}$ Moist Forest Research Station, Forestry Research Institute of Nigeria, Benin City, Nigeria \\ ${ }^{2}$ Wesley University of Science and Technology, Ondo, Nigeria
}

\begin{abstract}
In addressing the problem of ill-health and risks associated with the use of pesticides, health and safety practices were advocated among cocoa farmers in the area. The study was therefore conducted to investigating safety options the farmers were aware of as well as the factors influencing their adherence to the safety precautions. Descriptive statistics and Ordered probit model were used to analysed data collected from 480 respondents using multi-stage sampling technique. Descriptive statistics revealed that the average age of the farmers was $54 \pm 12.5$ years. Farmers were aware of the use of eye glasses, nose mask, mouth cover, protective clothing, protective boot, hand glove as well as washing/bathing after application and disposing off chemical container but adopt only the protective boot, protective clothing and wash/bath after application. Farmers' adherence to safety practices in the area was influenced by age, number of extension contact, cocoa income, livestock income as well as level of education. It is therefore important for development organisations and relevant government agencies to put in place policy thrust that would improve extension service, educate farmers as well as encourage them on the need to strictly adhere to Safety Precautions in Pesticides Use for efficiency and health of farmers.
\end{abstract}

Key Words: Farmers, adherence, precautions, pesticides, cocoa, ordered probit

\section{Introduction}

Pests and diseases are major impediments to agricultural crops productivity and they are responsible for several economic problems such as poverty among farmers at micro level and poor export at macro level especially in developing countries.

To achieve sustainable agricultural productivity, poverty reduction and better export, the use of pesticides especially among farmers producing crops that are highly vulnerable to crop pests has been promoted (Sosan and Akingbohungbe, 2009). Cocoa, one of the major export crops in Nigeria is highly vulnerable to pest and diseases attack just like vegetables. The roles of pests and diseases on cocoa output have

*Corresponding Author: Owombo, P.T.

Email: owombopaul@gmail.com negatively impated its productivity and hence Nigeria's position in the world cocoa market (Tijani, 2006). The most economically important and widespread species is the brown cocoa mirid-Sahlbergella singularis H. (Hemiptera, Miridae) which accounts for 25-30\% yield loss annually (Sosan and Akingbohungbe, 2009). Other insect species of economic importance are the cacao pod borer-Characoma stictigrapta $\mathrm{H}$. (Lepidoptera, Noctudae), the shoot feeders, Anomis Leona Shaus, Earias biplaga W. (Lepidoptera-Noctuidae). The major diseases of cocoa are the cacao swollen shoot virus (CSSV) disease transmitted by mealybugs vectors - Plannococcoides njalences L., Planococcus citri R. and Ferrisiana virgrata 810 
C. (Homoptera-Pseudococcoidae) (Asogwa and Dongo, 2009). The fungus of importance are Phytophthora palmivora and the more virulent Phytophthora megakarga results in black pod disease which accounts for between $30-90 \%$ loss of cocoa (Rutherford, 2011).

Pesticides application has been the engine room of sustained cocoa productivity in Nigeria just like in other African countries (Rutherford, 2011). They have the capacity to either eliminate or reduce pests' effects below the economic injury level.

Despite the positive roles played by pesticides in keeping pest below the economic injury level, their use is associated with adverse health effects and risks. Donald (2006) revealed that the agricultural sector is one of the most hazardous to health worldwide. Agricultural work possesses several characteristics that are risky for health - exposure to the weather, close contact with animals and plants, extensive use of chemical and biological products. According to Laary (2012) and Tijani (2006), farmers' use of pesticides is characterized by gross misuse which aggravates the health problems associated with the pesticides use practices. Most agrochemicals are toxic and can pose danger to human health (WHO, 2008), hence, their use is highly regulated internationally, nationally and regionally, with regulations and conventions (PAR, 2000; FAO/WHO, 2001, Larry, 2012).

Pesticides use is not without safety or precautionary practices contained on the labels as well as advocated by relevant national and international agencies in every country (e. g. WHO, FEPA, NESREA etc, in Nigeria) which are expected to prevent farmers from iheath associated problems. Pesticides labels show the active ingredients and indicate other hazardous or dangerous ingredients (e.g. by showing dangerous goods symbols) and the use rules. Some packages of pesticides have labels that contain extensive information in booklet form that is inserted into an envelope or pocket on the container (Donald, 2006) which according to Adegbola et al. (2012) should be a drive for enforcement, enlightenment, campaigns, and awareness in changing the heart and minds of stakeholders especially grain and bean handlers and merchants to use pesticide in a manner that is consistent with the label or as define by regulatory bodies. Rutherford (2011) added that cocoa farmers should endeavour to practice safe and health risk reducing activities involving pesticides use.

Despite the safety and precautionary practices contained on the labels and booklets inserted on pesticides packages for ill-healthfree application, most framers still do not adhere to these precautions. Studies, Tijani (2004) investigated factors influencing pesticide use among cocoa farmers in Ondo state Nigeria, Asfaw et al. (2009) examined EU food safety standards, pesticide use and farm-level productivity, Sosan et al. (2008) determined insecticide residues in the blood serum and domestic water source of cacao farmers in Southwestern, Nigeria and Sosan and Akingbohungbe (2009) investigated occupational insecticide exposure and perception of safety measures among cacao farmers in Southwestern Nigeria. Rarely, however had any known study been conducted to assessing the determinants of adherence or otherwise of cocoa farmers in the study area to safety precautions associated with pesticides use in the study area. The study therefore answers the following pertinent questions: What are the pesticides (insecticides and fungicides) commonly used by the cocoa farmers in the area? What are the safety measures or precautions on the pesticides labels the farmers are aware of? What are their information sources? What are the factors influencing their non-adherence to the safety precaution bearing on pesticides labels? The need to provide answers to the above 
pertinent questions gives birth to a number of objectives.

\section{Objectives of the study}

The broad objective of the study is to assessing the factors influencing farmers' adherence to safety precautions on pesticides label among cocoa farmers in Nigeria. Specifically, the study identifies the pesticides (insecticides and fungicides) commonly used by the respondents; indentifies the common safety precautions or practices the farmers are aware of; assess the information sources of the respondents on safety options and determine the factors influencing cocoa farmers adherence to safety precautions or practices.

\section{Methodology}

\section{Study Area}

The study was conducted in the Southwestern, Nigeria which is the major cocoa production belt of the Country. The zone is made up of Six States-Ekiti, Ogun, Lagos, Ondo, Osun and Oyo States. The zone is purposively selected for the study base on the predominance of cocoa production in the area. The zone lies between Longitude $4^{\circ} 30^{\prime}$ and $6^{\circ} 0^{\prime}$ east of the Greenwich Meridian and Latitude $4^{\circ} 45^{\prime}$ and $8^{\circ} 15^{\prime}$ north of equator. The zone is a tropical coastal wetland with mean annual rainfall approaching $2800 \mathrm{~mm}$, mean number of rainy days of between 160 and 180. Mean relative humidity is between $70-80 \%$, mean annual temperature is about $28^{\circ} \mathrm{C}$, mean daily temperature is $26^{\circ} \mathrm{C}$, mean daily minimum temperature is $22^{\circ} \mathrm{C}$, and mean daily maximum temperature is $26.7^{\circ} \mathrm{C}$ (ref.). The land in the area is characterized by varying physical features like hills, lowland, rivers, creeks and lagoons. The people are predominantly smallholder farmers cultivating both permanent plantation crops like cocoa, cola, oil palm, etc. for cash and arable crops like yam, cassava, maize and cocoyam, etc. for the dual purpose of family consumption and cash. Farming activities are usually carried out using simple farm tools with limited application of modern implements. Farming is the major occupation in most of the Southwestern States.

\section{Sampling Techniques and Data Collection}

Multistage sampling technique was employed to select respondents for the study. The first stage involved purposive selection of Ekiti, Ondo and Osun States, Southwestern, Nigeria, based on the level of involvement in the enterprise. In the second stage, 4 Local Government Areas (LGAs) were purposively selected in each of the states based on the predominance of cocoa production in those LGAs making 12 LGAs. In the third stage, two villages per LGA were randomly selected making a total of 24 villages in all. In the final stage, 20 cocoa farmers were randomly selected for interview. A total of 480 respondents were selected in all. Data were collected on the socio-economic and institutional characteristics of the respondents such sex, age, credit access, level of education, information sources, off-farm income, farming experience; farm factors such as farm size and safety practices or precautions (protective cloth, boot, nose mask etc) adhered to. Primary data were used for the study. Data collected were analyzed using SPSS version 16.0 and LIMDEP version 7.0.

\section{Analytical Technique}

Descriptive statistics and Ordered probit model were employed for analysis. Descriptive statistics was employed to analyse the pesticides (insecticides and fungicides) commonly used by the respondents; common safety precautions or practices the respondents were aware of; socio-economic characteristics of variables used while ordered probit model was used to determine the factors influencing cocoa farmers adherence to safety precautions.

Farmers adherence options appear as a discrete choice set rather than a continuous one. When the dependent variable takes more 
Assessing Factors Affecting Adherence to Safety Precautions..................WOMBO et al.

than two values, but these values have a natural ordering, as is common in survey responses, the ordered probit model is often appropriate (Nagenthirarajah and Thiruchelvam, 2012). The Ordered Probit model is an extension of the binary probit model that can be used in cases where there is discrete dependent variables (Mafuru, 2007; Nagenthirarajah and Thiruchelvam, 2012). Most studies (Reardon and Vosti, 1995; Akinola and Owombo, 2012) have employed binary probit and Deji et al. (2012) logit models in their limited dependent variable studies. The discrete nature of the dependent variable in the study makes ordinary least squares regression model inappropriate. However, Probit or logit models are utilized for dichotomous dependent variables. In this study, multinomial model for discrete choice of ordered data is more applicable for this data analysis. Nevertheless the ordered probit model, which can make full use of every response choice, is statistically more efficient than the binary logit and probit model (Nagenthirarajah and Thiruchelvam, 2012). Therefore, the follwing ordered probit model that uses Maximum Likelihood (ML) analysis (Nagenthirarajah and Thiruchelvam, 2012) was employed in this study. Models for discrete dependent variables can be formulated as a threshold model with a latent dependent variable:

$Y^{*}=B_{i} X_{i}+\varepsilon$

Where, $\mathrm{Y}_{\mathrm{i}}{ }^{*}$, is dependent variable

$X_{\mathrm{i}}=$ independent variables

Equation 1 above can be specified empirically as follows:

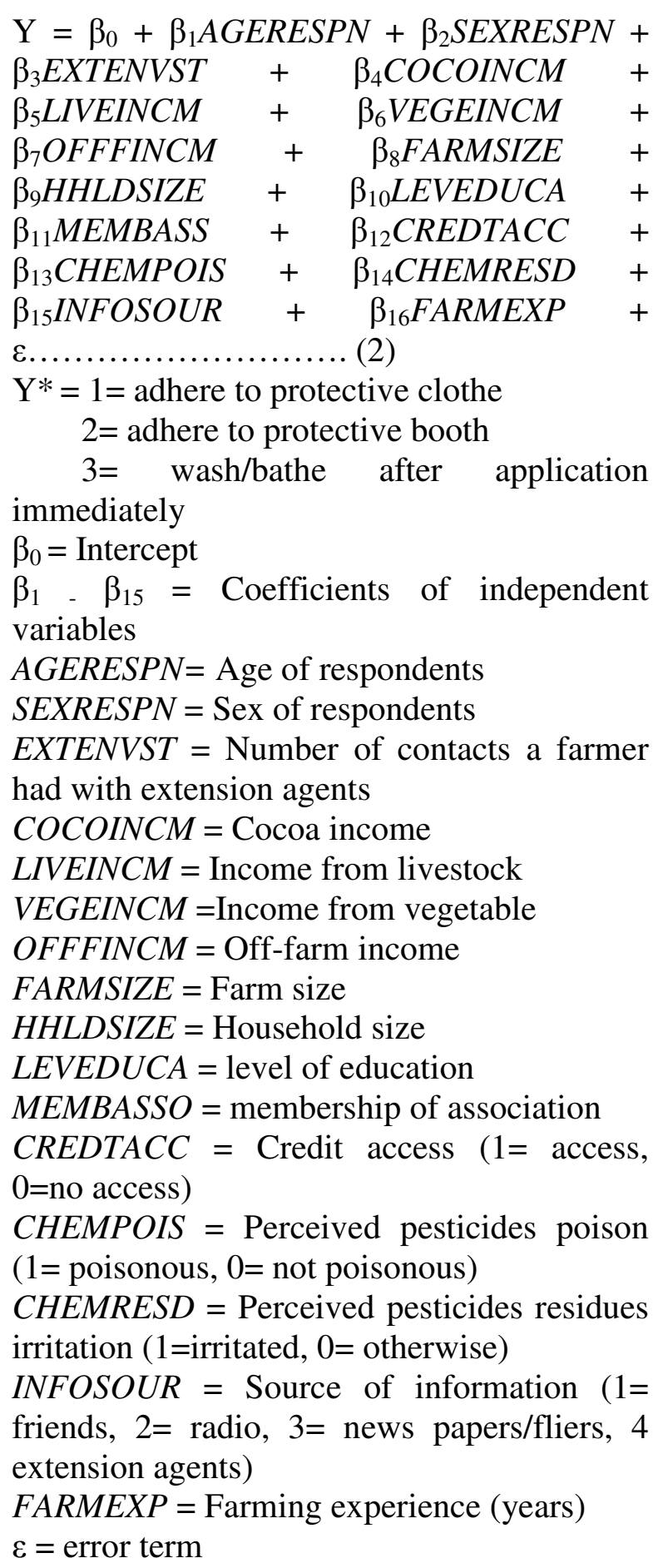

$\varepsilon \ldots \ldots \ldots \ldots \ldots(2)$

$2=$ adhere to protective booth

immediately

$\beta_{0}=$ Intercept

$\beta_{1}-\beta_{15}=$ Coefficients of independent variables

$A G E R E S P N=$ Age of respondents

SEXRESPN = Sex of respondents

had with extension agents

COCOINCM = Cocoa income

LIVEINCM = Income from livestock

$V E G E I N C M=$ Income from vegetable

$F A R M S I Z E=$ Farm size

HHLDSIZE = Household size

$\angle E V E D U C A=$ level of education

$M E M B A S S O=$ membership of association

$0=$ no access)

CHEMPOIS = Perceived pesticides poison

( $1=$ poisonous, $0=$ not poisonous $)$

CHEMRESD $=$ Perceived pesticides residues irritation ( $1=$ irritated, $0=$ otherwise)

INFOSOUR = Source of information $(1=$ friends, $2=$ radio, $3=$ news papers/fliers, 4 extension agents)

$\varepsilon=$ error term 
Table 1: Expected signs of independent variables

\begin{tabular}{|c|c|}
\hline Variable & Sign \\
\hline AGERESPN & $+/-$ \\
\hline SEXRESPN & $+/-$ \\
\hline EXTENVST & + \\
\hline COCOINCM & + \\
\hline LIVEINCM & + \\
\hline VEGEINCM & + \\
\hline OFFFINCM & + \\
\hline FARMSIZE & + \\
\hline HHLDSIZE & - \\
\hline LEVEDUCA & + \\
\hline MEMBASSO & + \\
\hline CREDTACC & + \\
\hline CHEMPOIS & + \\
\hline CHEMRESD & + \\
\hline INFOSOUR & + \\
\hline FARMEXP & $+/-$ \\
\hline
\end{tabular}

\section{Results and Discussion}

Socio-economic Characteristics of Respondents

The results of the socio-economic characteristics of the respondents are contained in Table2. The table reveals that the means of age, number of extension contacts the respondents had and farming experience were $54 \pm 12.5,6 \pm 14$ and $17 \pm 6$, respectively. This implies that the cocoa farmers in the area were still in their active ages. The means of income from cocoa, livestock, vegetable and off-farm income were US\$1,637.27 \pm 701.3 ; US\$62.19 \pm 18.61 ; US\$27.45 \pm 7.44 and US\$153.98 \pm 101.63 , respectively. It could be inferred from the above income sources that cocoa farmers in the area engage in other non-cocoa farm as well as off-farm activities from which they earn income. The involvement of the cocoa farmers in other farm and non-farm activities might be due to the need to guide against income failure from cocoa. The mean farm and household sizes were $2.5 \pm 8$ acres and $7 \pm 4$, respectively. This implies that the farm size in the area is low and the high household size might reduce cost of labour hire in the area. The mean numbers of years spent in school by the respondents were $5 \pm 4$ in the area. This implies that the cocoa farmers in the area hardly completed primary school in the 6-3-3-4 system of education in the country, Nigeria.

On association membership, while $49 \%$ of the respondents indicated their belongingness to one or two associations, $51 \%$ indicated none membership. The membership of the reasonable proportion of the respondent in association might be the reason for friends as major source of information. Furthermore, while just $17 \%$ of the respondents had access to credit, $83 \%$ of them do not have access to credit. The low credit access might result in poverty and hence none adherence to safety practices as the adherence to some requires capital outlay such as purchase of boot, clothe, glasses etc. All the respondents admitted that pesticides are poisonous. Analysis also shows that while $79 \%$ of the respondents admitted that the pesticides had irritating tendency, $21 \%$ indicated no irritation. The results of the socio-economic characteristic further revealed that while 68 percent of the respondents indicated friends as major information source, $13 \%$, and $19 \%$ indicated radio and extension agents as major sources of information in the study area. However, 
none of the respondents indicated news paper or fliers as information sources. The reason for the above might be due to the low level of education of the respondents in the area.

\section{Distribution of Respondents by Insecticides and Fungicides Used}

Figures 1 and 2 reveals the distribution of the respondents by the type of insecticides and fungicides used, respectively. Figure 1 revealed that majority of the respondents $(24.4 \%)$ used ACTARA insecticide followed by BASUDEN (20.9\%) and CYPMEBAN $(20.3 \%)$, respectively. However, while $11.7 \%$ of them used AVESTRIN, $10 \%$, $1.4 \%, 0.6 \%, 1.4 \%, 0.9 \%, 0.6 \%$ and $7.7 \%$ used CYMBUSH, GAMILIN EXTRAFORA ROCKET, GAMALIN 20,ALDRAX40, MASTER, PERFECT KILLER, DURSBAN EC48 and COBRA, respectively.

The result of the distribution of respondents by the fungicides used on their respective farms is shown in Figure 2. RIDOMIL GOLD is the most popular brand of insecticide used by majority $(42.7 \%)$ of the respondents in the study area. This is closely followed by PERENOX-Copper SOLUTIONS $(42.4 \%)$ and RIDMILFUNGURAN 7.7\%. However, $0.3 \%$ each used RIDOMIL-RED Free, RIDMILNORDOX, RIDMIL-CHAMP-NORDOX and RIDOMIL-FUNGURAN-ULTIMAX on their plots, respectively.

\section{Distribution of respondents by safety practices they are aware of}

Safety practices that the respondents in the study area claimed awareness of are presented in Table 3. The table revealed that about $99.3 \%$ of respondents in the study area indicated awareness of the use of protective clothing during application of the pesticides. Nose masks and eye glasses are also parts of the safety practices that the respondents were aware of as $98.2 \%$ indicated awareness of nose mask and $98 \%$ indicated awareness of the use of eye glasses. While $87.5 \%$ of the respondents indicated awareness of mouth cover, $79.9 \%, 88.9 \%$ and $64 \%$ of the respondents indicated the awareness of protective boot, wash/bath after application immediately and glove usage. However, just $22.6 \%$ of the respondents indicated the awareness of disposing off chemical containers when empty.

\section{Adherence Typology}

Figure 3 reveals the cocoa farmers adherence typology. The figure reveals that while majority $(54 \%)$ of the respondents indicated non-adherence to safety practices, $11 \%, 7 \%$ and $28 \%$ indicated adherence to the use of protective clothe, protective boot and washing and bathing immediately after application. It can be implied from the figure that despite mass awareness of safety practices by the respondents, a vast majority of them still do not adhere to safety practices they were aware of. The low rate of use of safety materials or adherence to safety practices among small scale farmers agrees with (Nagenthirarajah and Thiruchelvam, 2012).Despite the mass awareness of the safety practices by the farmers in the area, a good number of the practices were not adhered to. The non-adherence of the farmers to safety practices might be due to socioeconomic and institutional factors of the farmers.

Ordered probit results for farmers adherence to safety precautions or practices

The estimated coefficients and the marginal effects for the adherence of cocoa farmers to safety practices are given in Table 4. The Log likelihood and the Restricted log likelihood estimate were -169.1137 and 206.5230, respectively, and were significant which shows the fitness of the model. The analysis shows that farmers adherence to safety practices increases by number of extension contact and decreases with age of the farmers. An increase in the number of extension contact by 1 will result in an 
increase in farmers' adherence to protective clothing, protective boot and wash and bath after application by $7.48 \%, 5.2 \%$ and $2.28 \%$, respectively. Also, an increase in the age of the farmers by 1 year will decrease their probability of adherence to protective clothing, protective boot and wash/bathe after application by $1.17 \%, 25.44 \%$ and $11.16 \%$, respectively. Similarly, cocoa income, livestock income and off-farm income increase farmers' adherence to safety practices. An increase in cocoa income by US\$1 will increase farmers' adherence to protective clothing and protective boot by $2.1 \%$ and $1.44 \%$, respectively. In the same vein, an increase in livestock income by US\$1 will increase probability of adherence to protective clothing and protective boot by $2.14 \%$ and $1.49 \%$, respectively. Also, an increase in off-farm income by US $\$ 1$ will increase probability of adherence to the use of protective clothing and protective boot by $4.16 \%$ and $2.11 \%$, respectively. Analysis further revealed that while level of education increases farmers adherence to safety practices, credit access decreases farmers' adherence. An increase in level of education by 1 unit will increase farmers' adherence to protective clothing, protective boot and wash/bathe after application by $1.04 \%$, $2.03 \%$ and $12.01 \%$, respectively. However, an increase in the amount of credit a farmer accessed by 1 naira will decrease farmers' adherence to protective clothing and boot by 1 percent each. This implies that the credit accessed might be used for purposes other than farming. This does not agree with the expectation of the study but conforms to Kabubo-Mariaura et al. (2010).

\section{Conclusion}

It has been established that cocoa farmers are dependent on varying types of pesticides to control pests and diseases on their plots. The inherent ill-health and risks associated with the use of pesticides has led to advocates for the safe use of pesticides. Therefore, it becomes imperative to investigate factors influencing farmers' adherence to the use of these safety practices. Farmers in the area were adhered to the use of protective clothing, protective boot as well as wash/bathing immediately after use while the use of eye glasses, nose mask, mouth cover, hand glove as well as disposing chemical containers were not adhered to. While age of respondents adversely influenced farmers' adherence to safety practices, number of extension contact, cocoa income, livestock income, off-farm income and level of education positively influenced farmers' adherence to safety practices. A policy aimed at increasing farmers' income sources as well as educate them should be put in place by government, her agencies and development organisations in order to boost rate of adherence of cocoa farmers to safety precautions associated with pesticides use. 
Assessing Factors Affecting Adherence to Safety Precautions................WWOMBO et al.

Table 2: Socio-economic characteristics of respondents

\begin{tabular}{lll}
\hline Variable & Mean & Std Dev. \\
\hline Age of respondents & 54 & 12.5 \\
Number of extension contact & 6 & 14 \\
Farming experience (year) & 17 & 157,090 \\
Cocoa income (US\$) & 263,600 & $33,601.2$ \\
Livestock income (US\$) & $10,012.4$ & $4,039.3$ \\
Vegetable income (US\$) & $4,419.2$ & $89,137.8$ \\
Off-farm income (US\$) & 24,790 & 8 \\
Farm size (hectare) & 2.8 & 4 \\
Household size & 7 & 5 \\
Level of education (years) & 7 & 0.43 \\
Membership of association & 0.25 & \\
Yes & 49 & 0.43 \\
No & 51 & \\
Total & 100 & \\
Credit access & & \\
Yes & 17 & \\
No & 83 & \\
Total & $\mathbf{1 0 0}$ & \\
Perceived pesticides poison & & \\
Poisonous & 100 & \\
Not poisonous & 0 & \\
Total & $\mathbf{1 0 0}$ & \\
Perceived residue irritation & & \\
Has irritation & 79 & \\
No irritation & 21 & \\
Total & $\mathbf{1 0 0}$ & \\
Major information source & & \\
Friends & 68 & \\
Radio & 13 & \\
News paper/fliers & 0 & \\
Extension agents & 19 & \\
Total & $\mathbf{1 0 0}$ & \\
\end{tabular}


Ethiopian Journal of Environmental Studies and Management Vol. 7 Suppl. 2014

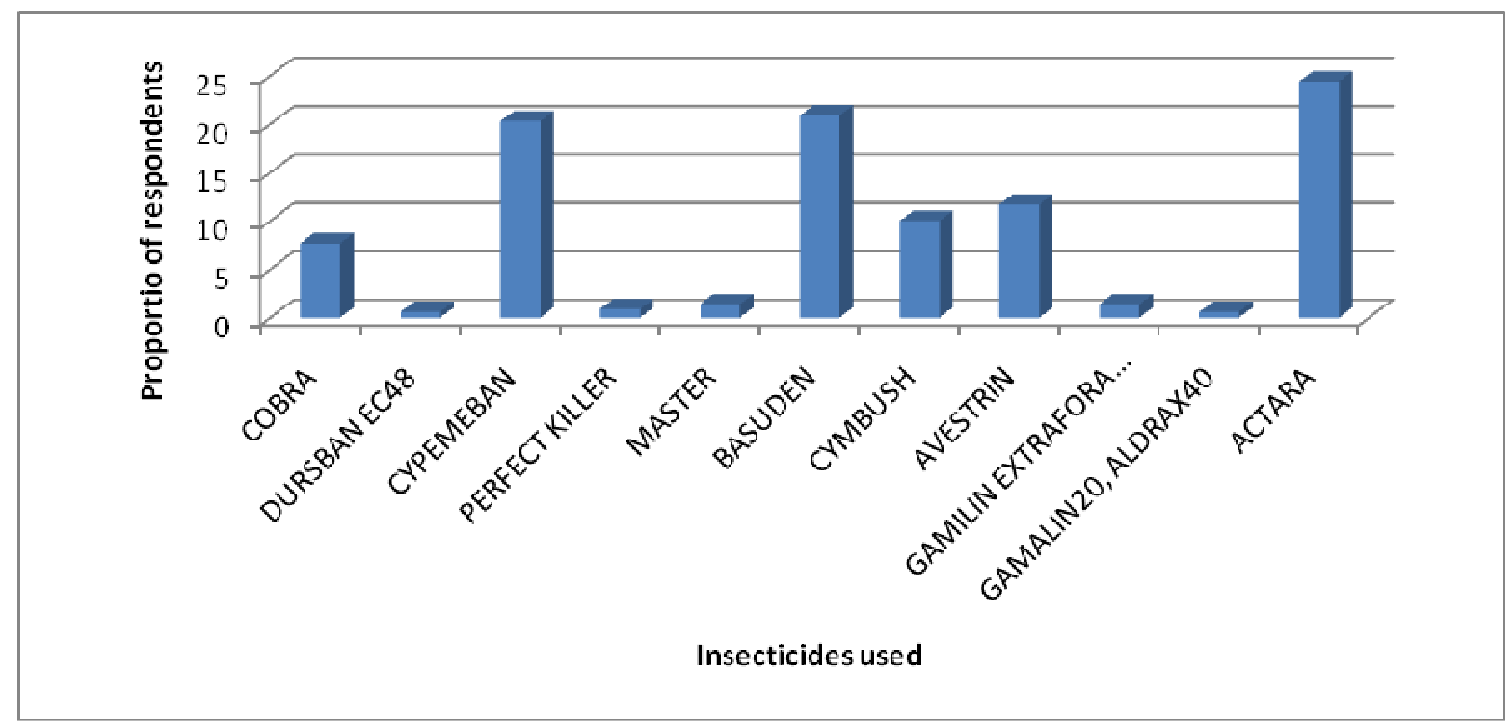

Figure 1: Distribution of respondents by insecticides used

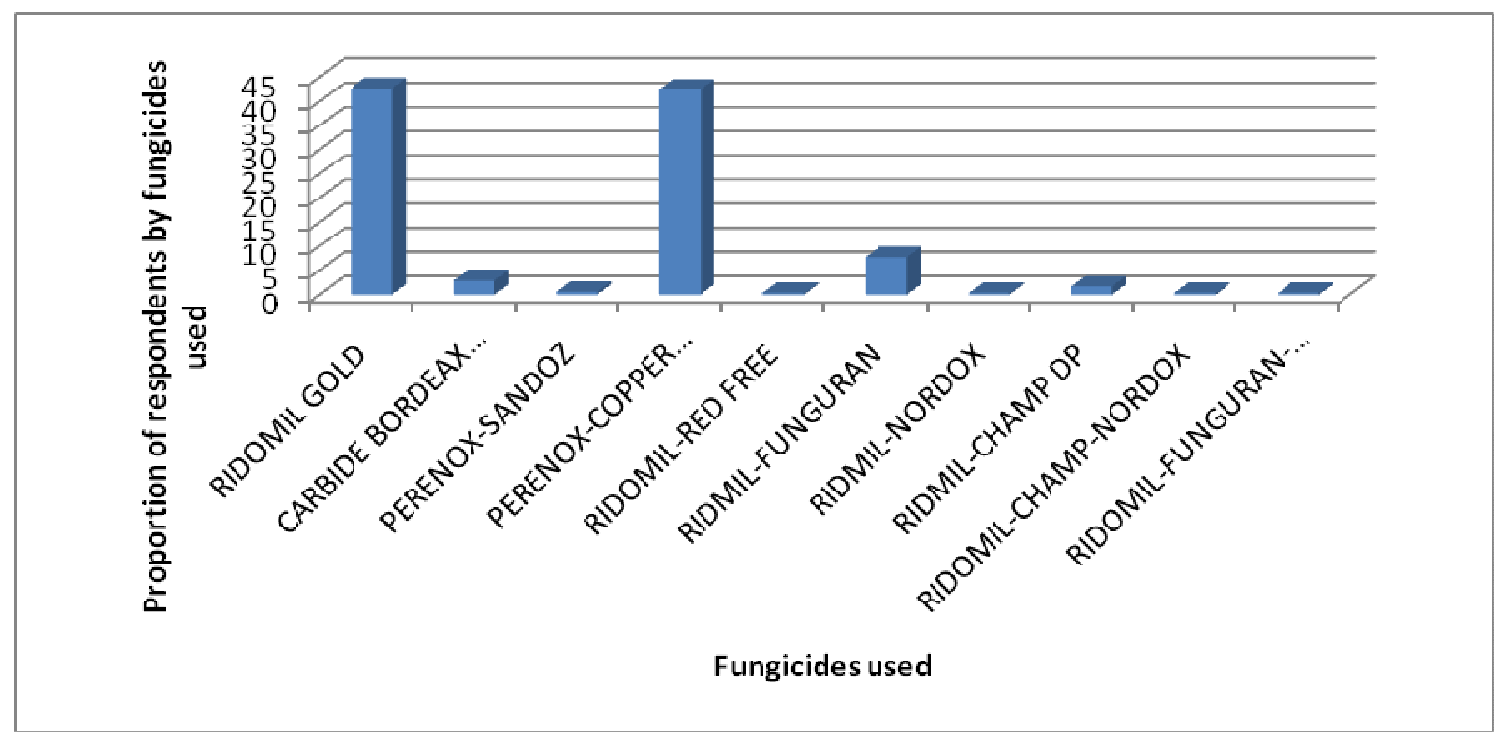

Figure 2: Distribution of respondents by fungicides used

Table 3: Safety practices aware of by respondents

\begin{tabular}{ll}
\hline Safety practices aware of & Percent of respondents \\
\hline Eye glasses & 98 \\
Nose mask & 98.2 \\
Mouth cover & 87.5 \\
Protective clothe & 99.3 \\
Protective boot & 79.9 \\
Wash/bath after application & 88.9 \\
Hand glove & 64 \\
Dispose off chemical container & 22.6 \\
Average & 79.8 \\
\hline
\end{tabular}




\section{Multiple Responses}

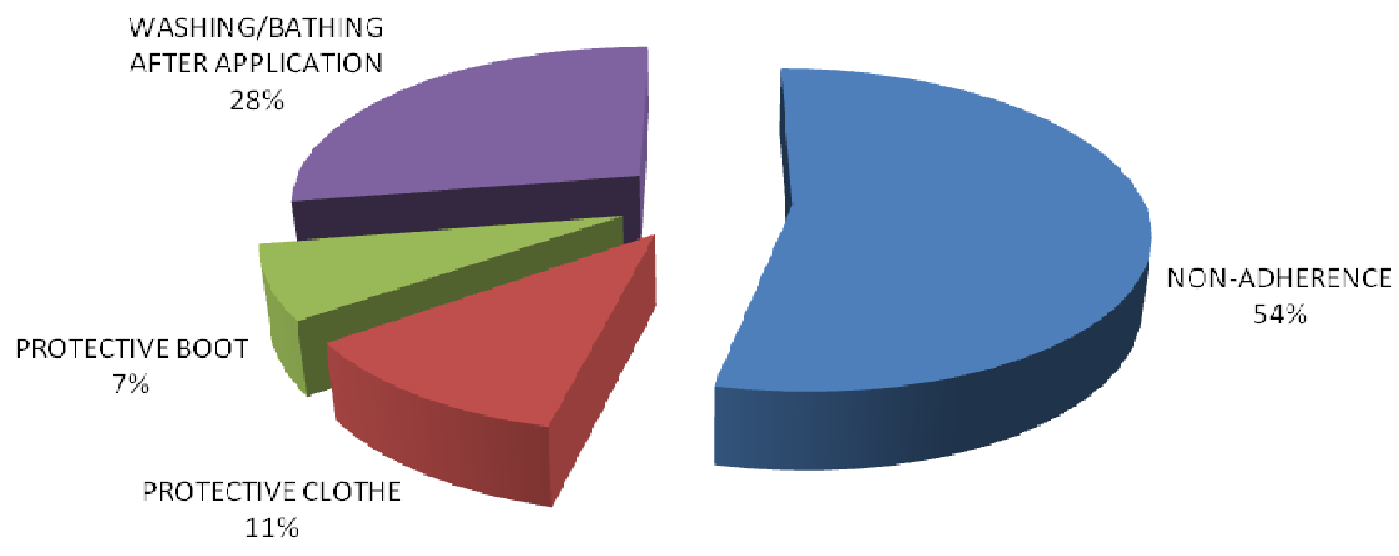

Figure 3: Farmers adherence typology

Table 4: Ordered probit model results for farmers adherence to safety practices

\begin{tabular}{lllll}
\hline Variable & Joint Coefficients & Marginal Effect & & \\
\cline { 3 - 5 } & & Protective clothe & Protective boot & Washing/Bathing \\
\hline AGERESPN & $0.0044^{* *}(0.0064)$ & $-0.0017^{* *}$ & $-0.2544^{* *}$ & $-0.1116^{* *}$ \\
SEXRESPN & $0.0047(0.289)$ & 0.0018 & 0.0013 & 0.0086 \\
EXTENVST & $0.1925^{* * *}(0.194)$ & $0.0748^{* * *}$ & $0.0520^{* *}$ & $0.0228^{* *}$ \\
COCOINCM & $0.0534^{* * *}(0.447)$ & $0.0208^{* * *}$ & $0.0144^{* *}$ & 0.0063 \\
LIVEINCM & $0.0551^{* *}(0.0214)$ & $0.0214^{* *}$ & $0.0149^{*}$ & $0.0106^{*}$ \\
VEGEINCM & $0.3495(0.5197)$ & 0.0000 & 0.0000 & 0.0000 \\
OFFFINCM & $0.4087 * *(0.1831)$ & $0.0401^{* *}$ & $0.0211^{* *}$ & 0.0005 \\
FARMSIZE & $0.0327(0.9736)$ & -0.0127 & 0.0088 & 0.0039 \\
HHLDSIZE & $0.6830(0.190)$ & 0.0265 & -0.0184 & -0.0081 \\
LEVEDUCA & $0.0211 * * *(0.112)$ & $0.0104^{* *}$ & $0.0203 * *$ & $0.1201 *$ \\
MEMBASSO & $0.0187(0.278)$ & 0.0073 & 0.0050 & 0.0022 \\
CREDTACC & $0.0270 * * *(0.0170$ & $0.0100^{* * * *}$ & $0.0069^{* *}$ & 0.0030 \\
CHEMPOIS & $-0.1967(0.059)$ & 0.0076 & -0.0053 & -0.0023 \\
CHEMRESD & $0.0120(0.016)$ & $-0.005)$ & 0.0032 & 0.0014 \\
INFOSOUR & $0.1799(0.196)$ & -0.0699 & 0.0486 & 0.0213 \\
FARMEXP & $0.2318(0.613)$ & -0.0090 & 0.0063 & 0.0027 \\
Log likelihood & -169.1137 & & & \\
Restricted Log-l & -206.5230 & & & \\
\hline
\end{tabular}

\section{References}

Adegbola, J.A., Anugwom, U.D., Awagu, F. and Adu, E.A. (2012). The Concept of Withholding Period and Pesticide Residue in Grain Storage. Asian Journal ofAgriculture and Rural Development, 2(4): 598 - 603.

Akinola, A. and Owombo, P. (2012). Economic Analysis of Adoption of
Mulching Technology in Yam Production in Osun State, Nigeria. International Journal of Agriculture and Forestry, 2(1): 1-6

Asfaw S, Mithofer, D. and Waibel, H. (2009). EU Food Safety Standards, Pesticide Use and Farm-Level productivity: The case of high-value Crops in Kenya. Journal of Agricultural Economics, 60(3): 645-667. 
Asogwa, E.U. and Dongo, L.N. (2009). Problems associated with pesticide usage and application in Nigeria cocoa production: A review. African Journal of Agricultural Research, 4(8): 675683.

Deji, O.F., Owombo, P.T. and Koledoye, G. F. (2012). Impacts of Training in Oil Palm Processing Technologies among Small Scale Farmers in Ondo State, Nigeria. Journal of Agriculture and Biodiversity Research, 1(6): 85-90.

Donald, C. (2006). Understanding the Links between Agriculture and Health Occupational Health Hazards of Agriculture. For Food, Agriculture, and the Environment. (New South Wales Chemicals code of conduct)

Food and Agricultural Organization (FAO) / World Health Organization (WHO) (2001). Amount of Poor-quality Pesticides Sold in Developing Countries Alarmingly High. Press Release, 1st February, 2001. Rome.

Kabubo-Mariaura, J., Linderhof, V., Kruseman, G., Atieno, R., and Mwabu, G. (2010). Household welfare, investment in soil and water conservation and tenure security: Evidence from Kenya. Environment and Development Economics, 15(2): 1-83.

Laary, J.K. (2012). Dry-Season Farming and Agrochemical Misuse in Upper East Region of Ghana: Implication and Way Forward. Journal of Agriculture, Food and Environmental Sciences, 5(1): 1-10.

Mafuru, J.M., Norma, D.W. and Langemeier, M.M. (2007). Ex-Ante Adoption Analysis for Improved Sorghum Varieties in the Lake Zone of Tanzania. African Crop Science Conference Proceedings, 8:1215-1219.

Nagenthirarajah, N. and Thiruchelvam, S. (2008). Knowledge of Farmers about Pest Management Practices in Pambaimadu, Vavuniya District: An Ordered Probit
Model Approach. Sabaramuwa University Journal, 8(1): 79-89.

Pan African Regulation (PAR) (2000). Pan Africa Regulation of Dangerous Pesticides in Ghana. Pan African Monitoring and Briefing Series No. 5, Dakar, Senegal, 16Pp.

Reardon, T. and Vosti, S. A. (1995). Links between rural poverty and the environment in developing countries. Asset categories and investment poverty. World Development, 23(9): 1495-1506

Rutherford, M. (2011). Assessing and addressing pesticide practice in cocoa producing countries to meet regulatory standards. International Workshop on Safe Use of Pesticides in Cocoa and Harmonized Legislation for Food Safety. Kuala Lumpur, 25-27.

Sosan M.B., Akingbohungbe, A.E., Durosimi, M.A., and Ojo, A.O. (2008). Insecticide Residues in the Blood Serum and Domestic Water Source of cacao Farmers in Southwestern Nigeria. Chemosphere, 72: 781-784.

Sosan, M.B., Akingbohungbe, A.E. (2009). Occupational Insecticide Exposure and Perception of Safety Measures among Cacao Farmers in Southwestern Nigeria. Archives of Environmental and Occupational Health, 64(3): 185-93.

Tijani, A.A. (2004). "Factors influencing pesticide use among cocoa farmers in Ondo state Nigeria" Second RUFORUM Biennial meeting 20-24 September 2010, Entebbe Uganda.

Tijani, A.A. (2006). Pesticide Use Practices and Safety Issues: The Case of Cocoa Farmers in Ondo State, Nigeria. Journal of Human Ecology, 19(3): 183-190

World Health Organization (WHO) (2008). Public Health and Environment and Quantifying Environmental Health Impact. (www.Who.int/topical environmentalhealth/en/. 